\title{
Coordenação do Comércio Atacadista de Pescado no Mercado do Ver-o-Peso, em Belém-Pará ${ }^{1}$
}

\author{
Abraão Oliveira Neto², Janaína Deane de Abreu Diniz ${ }^{3}$, \\ Wilma Marques Leitão ${ }^{4}$ e Dioniso Souza Sampaio ${ }^{5}$
}

Resumo: O Mercado do Ver-o-Peso em Belém do Pará é um dos principais pontos de desembarque e comercialização de pescado do Brasil. Por ele desembarcam 35 mil toneladas de pescado por ano para o abastecimento da região metropolitana de Belém, envolvendo centenas de trabalhadores, com destaque para os balanceiros, agentes comissionados que comercializam a produção dos pescadores no local. O presente trabalho tem o intuito de realizar uma análise sociológica das transações econômicas na tentativa de explicar os mecanismos de funcionamento deste mercado a partir de pressupostos da Sociologia Econômica, como confiança, reciprocidade e cooperação. A metodologia inclui revisões bibliográficas e documentais, entrevistas semiestruturas, observação direta e registros audiovisuais. A análise de conteúdo foi feita a partir da tabulação e classificação dos dados. Os resultados apresentados demonstram a importância do balanceiro como coordenador logístico das transações comerciais realizadas no comércio atacadista de pescado fresco na Pedra do Ver-o-Peso. Espera-se, com este trabalho, fornecer aos acadêmicos e gestores públicos do setor um olhar mais preciso, a partir de uma perspectiva baseada nas motivações individuais e coletivas, nas relações estabelecidas entre os agentes e na construção social dos mercados, onde a palavra-chave é a imersão social (social embeddedness).

Palavras-chaves: Ver-o-Peso; Comércio de pescado; Embeddeness; Sociologia econômica.

Abstract: The Ver-o-Peso Market, freely translated as "check-the-weight" market, is one of the main fish unloading and marketing sites in Brazil. Thirty five thousand tons of fish are unloaded yearly at the market, involving several groups of individuals, such as balanceiros, local conditioned agents who trade the local production. The present research intends to demonstrate, through Economical Sociology assumptions, the importance of balanceiros in

1. Data de submissão: 30 de abril de 2015. Data de aceite: 24 de maio de 2016.

2. Universidade de Brasília, Brasília, Distrito Federal, Brasil. E-mail: abraao@projepesca.com.br

3. Universidade de Brasília, Brasília, Distrito Federal, Brasil. E-mail: janadiniz@unb.br

4. Universidade Federal do Pará, Belém, Pará, Brasil. E-mail: wilma@ufpa.br

5. Universidade Federal do Pará, Bragança, Pará, Brasil. E-mail: sampaio.ds@gmail.com 
the fish commercialization model installed at Ver-o-Peso Market. The adopted methodology included bibliographic and documental research, semi-structured interviews, direct observation, audio and video registration. The analysis of the collected information was carried out through tabulation and ranking according to the assumptions of the Economical Sociology. The results demonstrate the importance of balanceiro as the logistical commerce coordinator of the transactions that are performed in the wholesale market of fresh fish on Pedra, the commercialization at the Ver-o-Peso Market. This study offers to the sector researchers and managers a perspective based on individual and collective motivations of the individuals involved in the establishment and development of local markets, in a context that goes beyond the economical assumptions of supply and demand, in a perspective that the keyword is social embeddedness.

Key-words: Ver-o-Peso; Seafood market; Embeddedness; Economical sociology.

DOI - http://dx.doi.org/10.1590/1234-56781806-94790540305

Classificação JEL: Q02

\section{Introdução}

Localizado em Belém, capital do segundo maior estado produtor de pescado do Brasil, o Pará, o Mercado do Ver-o-Peso é um dos principais pontos públicos de comercialização e distribuição de pescado do País (MPA, 2010). Na Pedra, como é comumente denominado o espaço de comercialização atacadista de pescado no complexo do Ver-o-Peso, desembarcam, em média, 27 toneladas de pescado diariamente, com intervalo de ocorrência de desembarque entre 18,5 e 33 toneladas diárias (BARTHEM, 2007).

Apesar de sua importância econômica e social, a Pedra é uma construção bastante rudimentar, de aproximadamente $1.600 \mathrm{~m}^{2}$, formada por um piso de cimento encerado, sem cobertura nem instalação hidráulica e que, durante o dia, serve apenas de passagem àqueles que transitam na região. Porém, durante as madrugadas, reúne centenas de trabalhadores em torno do comércio de pescado que abastece a região metropolitana de Belém (RMB) e outros centros consumidores regionais e nacionais.

A escolha do comércio realizado na Pedra do Ver-o-Peso como objeto de pesquisa é motivada pelos questionamentos quanto ao ordenamento e coordenação deste mercado frente ao conhecimento de que $60 \%$ das transações comerciais sejam realizadas no "fiado" (LEITÃO e CORRÊA, 2010, p. 126) e com registros feitos apenas em cadernetas de apontamentos. Quem são os agentes envolvidos no processo de distribuição destes produtos? Como centenas de pessoas se organizam para fazer funcionar este que é um dos principais mercados de pescado do Brasil? Quais as normas e regras para o seu funcionamento regular?

Além dos questionamentos acima apresentados, é importante inserir no contexto um fato externo que deverá alterar os arranjos de mercado no local: a construção de um Terminal Pesqueiro Público pelo governo federal, através do ministério da Pesca e Aquicultura que, com a justificativa da formalização da cadeia produtiva de pescado, utiliza o discurso de ofertar produtos pesqueiros a preços mais baixos à população pela ausência de intermediários ${ }^{6}$. Neste sentido, a presente pesquisa ocorreu em um momento anterior à intervenção governamental, sendo este um registro histórico de um modelo de comércio secular que poderá deixar de existir, ou que terá influência no futuro modelo de funcionamento do Terminal Pesqueiro. Nesse sentido, os resultados da pesquisa podem contribuir com uma análise da estrutura atual de operacionalização deste mercado e servir como um registro histórico de seu funcionamento antes da intervenção governamental.

6. http://www.mpa.gov.br/index.php/topicos/1026-em-programa-crivella-defendeconsumo-de-pescado-modernizacao-dapesca-e-expansao-da-aquicultura 
Para responder aos questionamentos apresentados, foram utilizados os conceitos relacionados aos canais de distribuição e à Nova Sociologia Econômica. Esta é uma pesquisa qualitativa de natureza descritiva, com recorte temporal transversal, uma vez que a coleta de dados foi conduzida por meio de observação direta, entrevistas semiestruturadas e gravações de áudio e de vídeo, que ocorreram em três viagens de campo realizadas entre maio e outubro de 2014.

\section{Fundamentação teórica}

\subsection{Os canais de distribuição e o pescado como produto logístico}

O Council of Logistics Management (CLM) define Logística como o processo de planejar, implementar e controlar o fluxo e a armazenagem de matérias-primas; o estoque durante a produção e produtos acabados; e as informações relativas a estas atividades, desde o ponto de origem até o ponto de consumo, visando a atender aos requisitos do cliente (CARVALHO NETO, 2009). Para Ballou (2006), o produto é o foco do sistema logístico, em que a análise dos atributos naturais de cada produto influencia na estratégia logística a ser adotada.

Os canais de distribuição podem ser analisados tanto pela perspectiva da distribuição física quanto pelos aspectos de marketing e vendas. A distribuição física envolve os processos operacionais e de controle que permitem a transferência do produto ao longo da cadeia. Já as questões relacionadas ao marketing e vendas envolvem os aspectos ligados à comercialização e transferência da propriedade. Os canais de distribuição são de difícil alteração, representando ganhos de eficiência de longo prazo por envolver diversos agentes e acordos comerciais que, com o passar do tempo, vão estabelecendo relações cada vez mais especializadas que permitem ganhos de eficiência e a concentração das empresas em seu core competence.

Assim, o uso de intermediários na distribuição deve ser visto como uma maneira de aumentar a eficiência do processo de produção e comercialização, aumentando o valor percebido pelo comprador. Tal fato ocorre em função da potencial diminuição de preço ao consumidor, pela redução de custos de busca e deslocamento (TELLES \& STREHLAU, 2006). Para Novaes (2007), o uso de intermediários não implica necessariamente em aumento de preço pela simples adição dos lucros dos agentes de intermediação.

Segundo Telles e Strehlau (2006), os fluxos logísticos podem ser classificados em cinco categorias distintas: o fluxo físico, o de propriedade, o de pagamentos, o de informação e o de promoção. Estes fluxos serão descritos mais à frente, já com os resultados da pesquisa.

\subsection{Os pressupostos da Sociologia Econômica}

A Sociologia Econômica caracteriza o agente econômico como motivado por razões não econômicas, em que "a economia do homem está submersa em suas relações sociais" (POLANYI, 2012, p. 48). Em A ação econômica e estrutura social: o problema da imersão, Mark Granovetter traz a ideia da "imersão" social (embeddedness) à ordem mercantil, idealizada por Polanyi. Para Granovetter (1985), a ação do agente econômico não pode ser explicada apenas por suas motivações individuais, pois elas são dependentes das contínuas relações sociais e as instituições são construções do processo evolutivo dos mercados a partir destas interações entre os agentes. Estas interações criam laços, regras e estabelecem e sofrem constantemente influências do meio externo, sejam eles o governo ou até mesmo o resto da sociedade muito além da mera maximização do lucro, o que assegura certa estabilidade nos mercados (BECKERT, 2007; SWEDBERG, 2003).

O objetivo da ação do agente econômico torna-se, então, a criação e manutenção de mundos estáveis dentro e entre as firmas envolvidas através de concepções de controle que permitam aos atores interpretar as ações dos outros e refletir sobre como o mercado está estruturado. A Sociologia Econômica centra-se na questão de como as redes sociais, as normas sociais, as 
estruturas cognitivas e instituições formais reduzem a contingência e o risco através da solução dos problemas de coordenação enfrentados pelos agentes do mercado (BECKERT, 2007).

Estes arranjos só podem ser estabelecidos se os agentes do mercado forem capazes de formar expectativas estáveis em relação às ações atuais e futuras dos outros agentes e se os resultados esperados são considerados normativamente aceitáveis, isto é, legítimos. Apenas quando os compradores estão confiantes de não serem explorados por seus parceiros de contrato é que eles vão se envolver em trocas de mercado. Criar essa confiança é, portanto, uma condição prévia fundamental das relações de mercado estáveis (BECKERT, 2007).

Por outro lado, Möllering (2006) ressalta que a redução dos riscos e incertezas nunca pode ser completa. A possibilidade de deserção de um agente está sempre presente no horizonte de expectativa dos atores e é apenas "suspensa" pela confiança entre os parceiros de troca em cooperação.

Desta forma, os arranjos de mercado consistem nos mecanismos que organizam a compra e venda e regulam o comportamento dos agentes dentro de um escopo de alternativas que asseguram certo grau de confiabilidade com sanções no caso do descumprimento dos acordos comerciais firmados (McMILLAN, 2004).

Para Fligstein (1996), estes arranjos construídos socialmente em formas de costumes e regras compartilhadas de direito de propriedade e governança possibilitam aos atores organizar suas ações, competir, cooperar e efetivamente realizar as transações econômicas.

Neste sentido, valores éticos como confiança, reputação, responsabilidade e até valores afetivos transformam-se em relações de reciprocidades capazes de gerar um sentimento de pertencimento social superior ao imaginado pela escolha racional, tanto pela transmissão do conhecimento como pela gestão dos recursos e dos fatores de produção. O contato face a face leva ao engajamento mútuo, à redução das assimetrias de informação e amplia a capacidade de inovação dos atores em evoluir suas normas e regras (SABOURIN, 2010, 2011).

"A lógica da reciprocidade pode constituir um motor da produção, e de uma produção de excedentes, tão poderoso como aquele da lógica da troca para a acumulação do lucro. Contudo, as relações de reciprocidade geram valores humanos que garantem modos de regulação capazes de estabelecer justiça e contra poderes podendo limitar os excessos, assim como foram propostas modalidades de regulação dos excessos do livre mercado. A diferença é que na hipótese da troca esses valores humanos ideais são supostamente constituídos entre os homens (teoria da justiça de Rawls). Na perspectiva da teoria da reciprocidade, esses valores não preexistem entre os indivíduos; eles devem ser constituídos, precisamente por meio de relações estruturadas de reciprocidade simétrica" (SABOURIN, 2011, p. 57).

Steiner (2006) cita o capital social como uma rede de relações mútuas de amizade entre indivíduos capaz de gerar um recurso real ou potencial que os indivíduos podem mobilizar para atingir seus objetivos. O capital social depende das ações dos membros da rede. A honestidade e a confiança constituem, assim, uma forma de capital social dentro de uma rede, seja por sua honestidade intrínseca ou em razão da pressão social que o grupo exerceria sobre um de seus membros que não cultivasse a norma esperada. Pertencer a um grupo por si só significa um capital social intangível, capaz de tornar desnecessárias certas precauções, como a formalização de contratos. A própria formalização de contratos muitas vezes significa, para muitos empreendedores, uma demonstração de falta de confiança nas realizações das transações.

Putnam (1993) refere-se ao capital social como redes sociais que geram cooperação e colaboração, bem como regulam as regras de competição por meio da comunicação interpessoal e de intercâmbio formais e informais. 


\section{Metodologia}

Trata-se de uma pesquisa qualitativa de natureza descritiva, realizada por meio de uma abordagem dos canais de distribuição de pescado na Pedra no mercado do Ver-o-Peso.

A primeira etapa da pesquisa envolveu a revisão bibliográfica e a identificação dos agentes e dos fluxos logísticos nas operações comerciais realizadas no local, com base em Telles e Strehlau (2006), os quais classificam os fluxos logísticos em cinco categorias distintas: o fluxo físico, o de propriedade, o de pagamentos, o de informação e o de promoção.

Após as fases de identificação dos fluxos logísticos e dos agentes envolvidos, iniciou-se a fase de aprofundamento dos temas relacionados à Sociologia Econômica e sua relação com o funcionamento do mercado do Ver-o-Peso.

Não foi necessária a definição de uma amostra significativa, uma vez que, logo no início das observações, foi percebido um padrão de comportamento claro entre todos os agentes. Além disso, não foram tratados as sazonalidades e os rearranjos na organização do mercado no que se refere aos tipos de produtos disponíveis (safras), e às atividades (festivas e religiosas, por exemplo), uma vez que o objeto de análise eram as transações.

Uma vez que o pesquisador esteve inserido in loco no campo de pesquisa, a observação direta foi utilizada como base de percepção de fatos, captação de informações referentes aos diálogos entre os agentes, como captador das linguagens e detalhes como valores e denominações durante as transações.

Foram acrescidas a este processo metodológico gravações de áudios e vídeos durante o funcionamento do mercado que, de modo complementar, permitiram a análise a partir de diferentes perspectivas do contexto sociológico envolvido.

As entrevistas semiestruturadas foram realizadas in loco com sete dos cerca de 200 balanceiros, e tiveram como temas/pontos levantados: idade, o nível de escolaridade, o tempo no mer- cado e na função, as motivações e situações que os levaram ao exercício da atividade e informações sobre o relacionamento de cada agente no mercado através do número de pescadores "fidelizados" e o montante estimado de capital próprio em circulação no mercado, conforme questionário específico. As entrevistas serviram também de introdução para conversas informais com os balanceiros, bem como permitiram o acesso às negociações e falas entre os agentes observados, algumas delas registradas em áudio. Muitos desses diálogos foram imprescindíveis para a compreensão dos fatos observados.

Os registros fotográficos foram realizados ao longo do dia e da madrugada durante todas as visitas ao local, sendo as fotografias classificadas segundo categorias como identificação de agentes, caracterização dos ativos, momento de transação, simbologias e valores, normas de organização e procedimentos e serviços acessórios.

As gravações de áudio foram realizadas com o objetivo de registrar depoimentos a respeito do funcionamento do mercado, sejam eles as estruturas de negociação e o modo por meio do qual os agentes se relacionam. Os registros de áudio foram posteriormente revisados e os depoimentos importantes catalogados em planilha com registro do nome do arquivo, momento do registo (minuto e segundo), transcrição da fala relevante e significado da fala.

A análise de conteúdo foi realizada a partir da observação do fluxo operacional dos produtos pesqueiros e a tabulação dos dados em grupos relacionados à solução dos problemas de competição, cooperação e valor e subgrupos cujas temáticas estavam relacionadas à incerteza, confiança, os diretos de propriedade, mecanismos de governança, regras de troca e concepções de controle, seja pela operacionalização dos processos de transferência dos bens, pelo financiamento ou o fluxo de informações entre os elos. Estes conteúdos foram ainda classificados em institucionais, normas (internas), regras (estabelecidas com os agentes externos ao grupo), costumes e reciprocidade, sendo as informações tabuladas em planilha composta de três colunas: nome do arquivo 
com momento do registo (minuto e segundo) ou intervalo de tempo, fato relevante observado e classificação do conteúdo.

Richardson (1999 apud AUGUSTO et al., 2013) destaca que o objetivo da pesquisa qualitativa não reside na produção de opiniões representativas e objetivamente mensuráveis, mas na compreensão de um fenômeno social por meio de análise da consciência articulada dos atores envolvidos no fenômeno. Por esse motivo, a validade da pesquisa não se dá pelo tamanho da amostra, como na pesquisa quantitativa, mas, sim, pela profundidade com que o estudo é realizado.

Assim como Viana (2014) em sua pesquisa exploratória sobre as convenções sociais no mercado do café gourmet, esta pesquisa visa a "a interpretação e a atribuição de significados aos fenômenos estudados" (p. 53), em que sua observação esteve sempre direcionada ao papel do pesquisador como instrumento-chave, inserido no ambiente de pesquisa, como fruto de análise através da observação direta.

Com recorte temporal transversal, a pesquisa foi realizada a partir de 3 viagens de campo entre maio e outubro de 2014, com o objetivo de coletar os dados primários necessários para a análise de conteúdo e de discurso. Neste sentido, foram realizadas visitas de campo entre os dias 28 de maio a 01 de junho (duas visitas de campo com observação direta e gravação de entrevistas semiestruturadas), de 03 a 07 de setembro (novas observações diretas, coleta de áudio das transações e entrevistas semiestruturadas sem gravação) e de 08 a 14 de outubro, com coleta (autorizada) de imagens das câmeras de segurança do Centro Integrado de Operações da Polícia Militar do Estado do Pará (Ciop) e acompanhamento da participação dos agentes nas festividades do Círio de Nazaré.

\section{Resultados e discussão}

Com base em Ballou (2006), o principal atributo logístico do pescado é sua perecibilidade, representando uma característica de risco e exigindo ativos específicos como embarcações, caminhões frigoríficos, equipamentos em aço inoxidável para a manutenção a baixas temperaturas e a prevenção da proliferação de bactérias que podem comprometer a qualidade do produto. A perecibilidade, o cuidado no manejo do pescado e a necessidade de investimentos em ativos específicos para a atuação no mercado exige que os agentes se especializem em determinadas atividades ou verticalizem suas operações, sejam elas a pescaria, a venda ou a prestação de serviços correlatos como o transporte e armazenagem de acordo com os limites financeiros e a capacidade de execução de cada agente.

A descrição dos fluxos logísticos sugerida por Telles \& Strehlau (2006) inicia-se segundo os fluxos físico, de propriedade, de pagamentos, informação e promoção, conforme será descrito a seguir.

As atividades de desembarque, comercialização e distribuição de pescado no Ver-o-Peso ocorrem diariamente a partir da meia-noite e envolvem diversos atores divididos em dois mundos distintos: o meio aquático e o terrestre. No meio aquático, envolve pescadores e marreteiros ${ }^{7}$ com suas embarcações especializadas no transporte de pescado, conhecidas como Geleiras. Já no meio terrestre, balanceiros e compradores negociam a produção, enquanto que viradores e carregadores aguardam as negociações para iniciar o processo de escoamento do pescado fresco. Além desses, com o crescimento da malha viária, caminhões trazem peixes, tanto da pesca quanto da aquicultura, oriundos de outros municípios e até mesmo de outros estados para comercializarem na Pedra.

Os compradores são representados por feirantes, peixeiros (inclusive do Mercado do Peixe do próprio Ver-o-Peso, uma vez que na Pedra as vendas são no atacado) e compradores de restaurantes, supermercadistas e distribuidores de pescado de outras regiões do estado ou mesmo de grandes centros urbanos como Brasília, São Paulo e Rio de Janeiro (Figura 1).

7. Marreteiros são compradores de pescado que se deslocam em suas embarcações até as comunidades ribeirinhas comercializando mantimentos em troca de pescado seco e salgado que serão comercializados no Ver-o-Peso. 
Figura 1. Cadeia de suprimentos simplificada do Mercado de Pescado no Ver-o-Peso

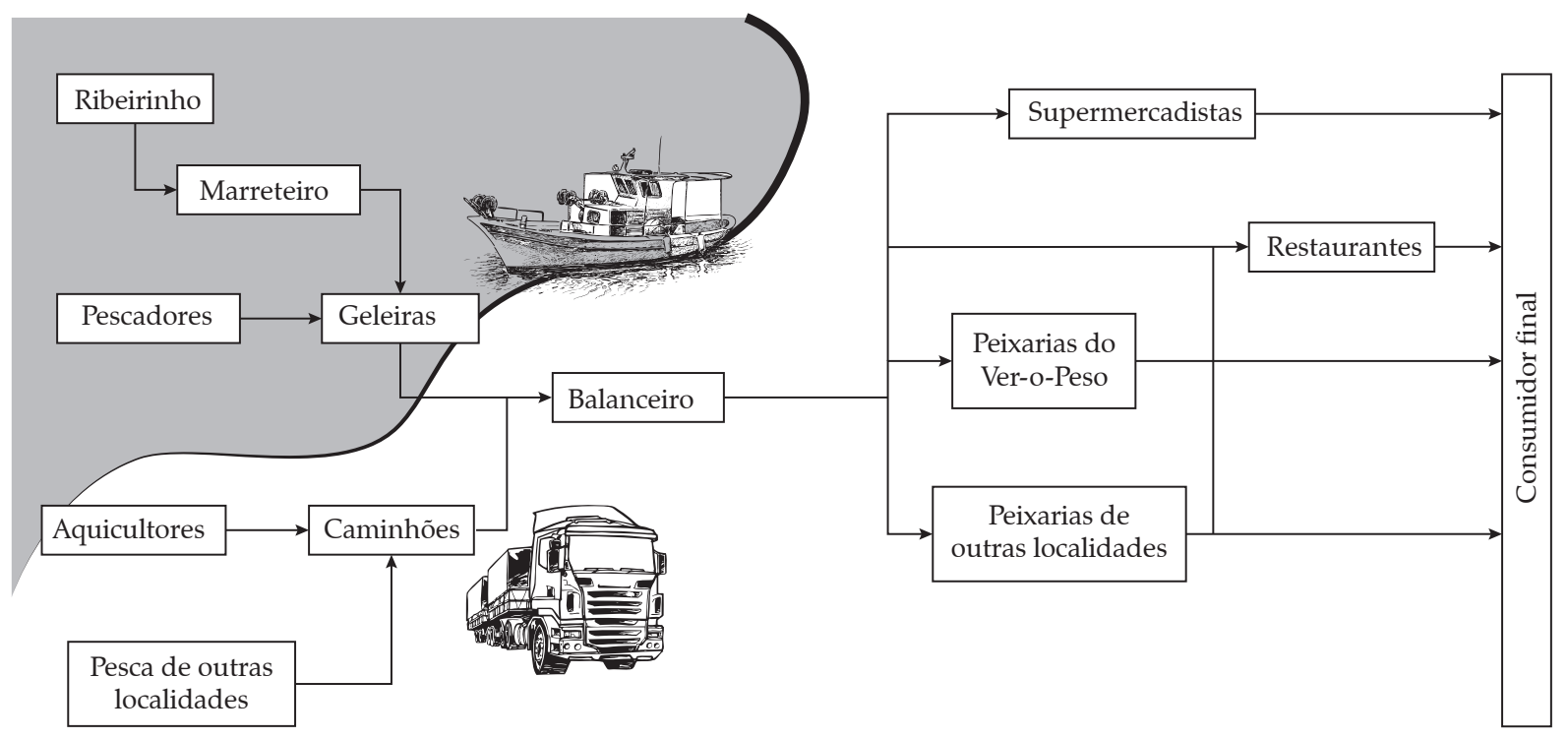

Fonte: Elaboração própria com base em pesquisa de campo.

A comercialização do pescado fresco ocorre via balanceiros, agentes comissionados instalados à margem do cais do mercado, com a função de vender a produção dos pescadores, fazer a troca de informações entre oferta e demanda, fazer a conferência dos pesos dos produtos comercializados e contratar serviços de carregadores para a transferência da produção das embarcações até os caminhões de transporte. Os balanceiros recebem por seu trabalho uma comissão de $6 \%$ do valor das transações (RUFFINO, 2007).

Os viradores, apesar de não aparecerem na figura, são auxiliares dos balanceiros, responsáveis tanto pelas pesagens quanto pela organização dos espaços de comercialização e exposição de venda, são pessoas de grande confiança dos balanceiros. Outros agentes envolvidos neste processo são os carregadores, trabalhadores que transportam o pescado até os veículos dos compradores. Os carregadores são facilmente identificáveis no mercado, por estarem sempre com suas caixas de madeira destinadas ao transporte de pescado e por utilizarem um círculo de tecido sobre a cabeça, que tem a função de facilitar o equilíbrio das caixas e reduzir o efeito do peso das mesmas sobre suas cabeças. As "caixas" são tablados de madeira originalmente utilizados nas importações de bacalhau seco e salgado da Noruega por supermercados da região e que são reutilizados na Doca do Ver-o-Peso para o transporte do pescado. As caixas suportam cerca de $100 \mathrm{~kg}$ de peixes.

Por volta da meia-noite, quando as portas da sede da Associação dos Balanceiros do Mercado do Ver-o-Peso (Asbalan) são então abertas, inicia-se a preparação da Pedra para a comercialização. Os viradores buscam as balanças depositadas na Asbalan e as instalam próximas às embarcações. Na entrada do depósito da Asbalan há um cartaz afixado na parede que comunica que apenas balanças aferidas pelo Instituto Nacional de Metrologia, Qualidade e Tecnologia (Inmetro) são permitidas no local. Este pequeno cartaz é o primeiro sinal de um agrupamento de normas estabelecidas entre os balanceiros para a manutenção da estabilidade desse mercado.

Um fato curioso é a organização espacial do comércio, onde, sem a referência de nenhuma marcação no piso, se repete diariamente o posicionamento das balanças e a formação dos mesmos 
corredores por onde trafegarão mais tarde, compradores e mercadorias.

Após o posicionamento das balanças, inicia-se a organização da exposição do pescado em caixas plásticas, com os peixes sendo separados por espécies e tamanho e perfilados harmonicamente nas caixas de exposição. São desembarcadas amostras dos produtos ofertados, já separadas por espécies durante a estocagem nas Geleiras. Nesta etapa, ocorre uma nova separação, agora por tamanho. Esta separação por tamanho é mais uma característica intrínseca dos mercados, pois através dela é possível aos compradores valorizar os produtos ofertados, comparando-os a outras ofertas similares no mercado.

Por volta de 1 hora da manhã, começam a surgir os primeiros compradores. Sua tarefa inicial é a busca de informações sobre as ofertas disponíveis. Essa busca é feita por uma rápida observação visual e consulta sobre os preços e padrões de qualidade das ofertas de interesse. Dentre os padrões de qualidade, são observados tamanho, uniformidade e frescor através de análise sensorial: visual e de odor, tanto das condições externas dos peixes como na área interna, uma vez que a maioria é comercializada eviscerada.
Após a coleta de informações, inicia-se a fase de negociação das condições das transações (preços, volumes e formas de pagamento) entre balanceiro e comprador. Depois de acordados os termos das transações, dá-se início ao processo de transferência de propriedade do pescado. $\mathrm{O}$ balanceiro assume o compromisso de operacionalizar o processo de transferência que ocorre por meio das etapas de desembarque, pesagem e transporte do produto para os veículos do comprador. Pescadores das geleiras desembarcam a produção comercializada em caixas contentoras que seguem para as mãos dos viradores, responsáveis por auxiliar o balanceiro nas pesagens e por realizar a troca de caixas de transporte, que vêm da embarcação por caixas dos compradores. Após o desembarque, os volumes solicitados são conferidos na presença do comprador e do balanceiro com todas as anotações sobre pesos e valores registrados em cadernetas de apontamentos. Pesados, os produtos são, então, entregues aos carregadores, que farão o transporte até os veículos dos compradores, conforme a Figura 2.

O fluxo comercial deste produto vendido deverá prosseguir durante o dia, quando, por

Figura 2. O momento da transação comercial. Destaque para (1) Balanceiro; (2) Comprador, (3) Virador e (4) Carregador

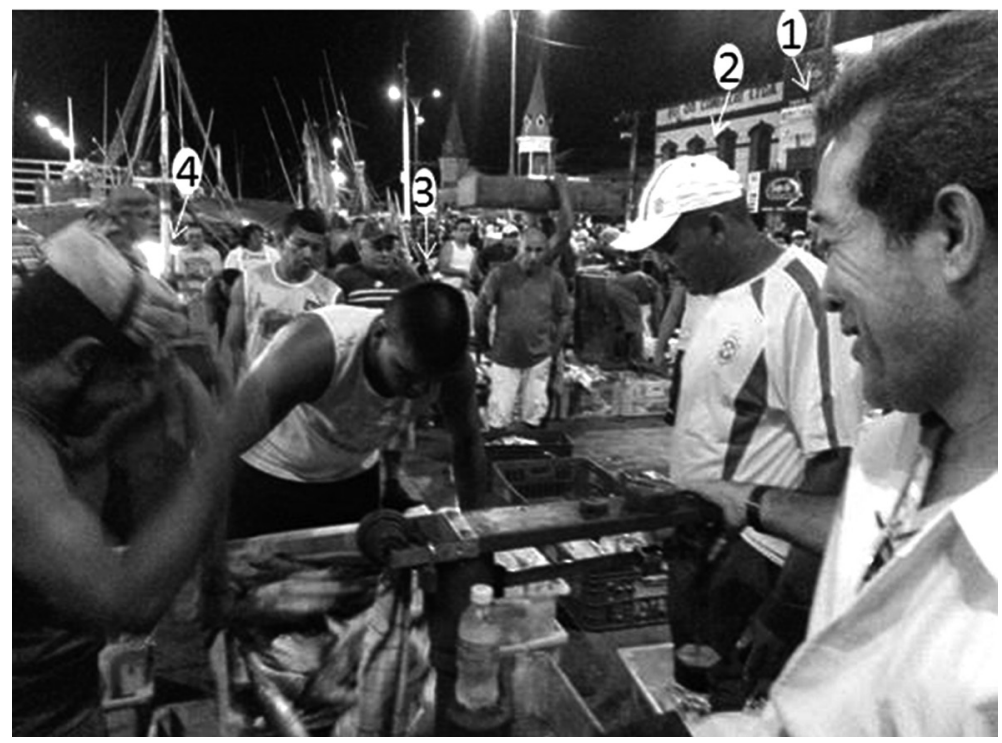

Foto: Oliveira Neto (2014). 
intermédio dos próximos agentes da cadeia peixeiros ou restaurantes -, o consumidor terá acesso ao pescado fresco. Vale salientar que os restaurantes podem adquirir o pescado por intermédio dos próprios peixeiros, como ocorre na praça de alimentação do Ver-o-Peso. Porém, estas novas transações não ocorrerão na Pedra do Ver-o-Peso e não podem ser caracterizadas como parte deste mercado, uma vez que serão novos agentes e em novas condições. Mesmo que se encontrem distantes poucos metros um do outro, são mercados distintos.

O fluxo físico envolve todos os agentes que repassam o produto ao seu sucessor na linha de responsabilidade, até o produto ser embarcado no veículo do comprador, conforme já descrito na seção anterior. Já o fluxo de propriedade é direto do pescador para o comprador, uma vez que a transação ocorre entre estes dois agentes, sendo o balanceiro apenas um intermediário da transação, não da propriedade. O fluxo de pagamentos é dividido em duas etapas independentes, nos quais o papel do balanceiro se faz imprescindível, sendo que o pagamento do comprador pode ser realizado após o fim da transação ou no fiado, dependendo da relação de confiança entre comprador e balanceiro. Já o pagamento do balanceiro ao pescador ocorrerá de imediato após o fim da venda de toda a sua produção, de maneira que o mesmo possa retornar ao seu porto de origem.
Todos estes processos são coordenados pelos balanceiros, que orientam os envolvidos quanto às ações a serem executadas e o momento de início e término de cada transação. A Figura 3 resume os cinco diferentes fluxos descritos anteriormente.

\subsection{Análise de Conteúdo Audiovisual}

A partir deste tópico são apresentados resultados da análise de conteúdo e de discurso das entrevistas realizadas.

\subsubsection{A promoção - competição}

Antes mesmo da abertura das vendas, cada balanceiro, em conjunto com os pescadores proprietários do pescado, define o preço de cada produto a ser ofertado de acordo com o histórico dos preços anteriores. A definição dos preços de venda é realizada entre cada balanceiro e o proprietário do pescado, seja ele pescador ou aquicultor, e que, pessoalmente, ou por meio de pessoa de sua confiança, acompanha todo o processo de comercialização de sua produção.

“Essa média aí é oito, amigo! [...] de oito só tem esse pouco já aí, ó!", nesta fala, o balanceiro 1 oferta ao possível cliente um determinado volume de pescado classificado por tamanho. No jogo da negociação, o comprador 1, tentando baixar o preço do pescado e já interessado no lote com a mesma espécie de pescado, mas de tama-

Figura 3. Fluxos logísticos no mercado do Ver-o-Peso

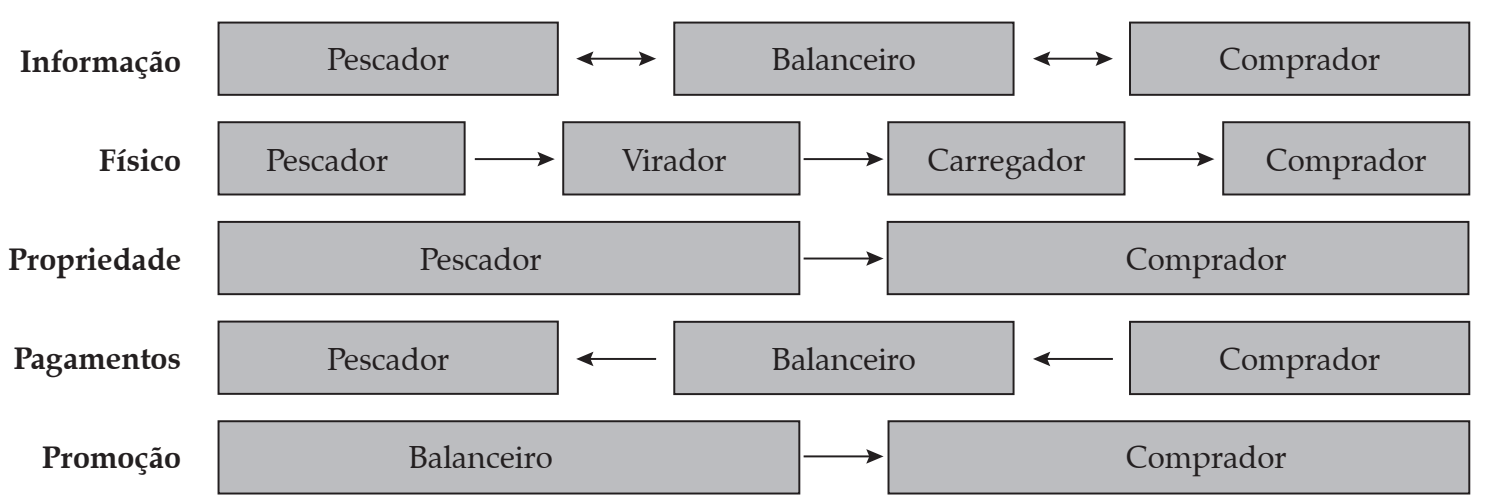

Fonte: Elaboração própria com base em pesquisa de campo e adaptado de Telles \& Strehlau (2006). 
nho ainda maior, comenta: "eu vi de seis ali". Meio que ofendido, o balanceiro 1 responde: "outro dia tu tava me pagando de quinze isso, tô te pedindo dez. Dez reais essa escolhida! Compre lá, pai".

Mas o comprador 1 se mantém na negociação, mesmo após comentar que viu o mesmo pescado a seis reais e procura um desconto: "essa de dez, tem preço pra caixa?"

Baixando novamente o tom da conversa, o balanceiro 1 responde que gostaria de vender a doze mas está sendo obrigado a ofertar por dez: "na verdade, a gente queria de doze, tô vendendo de dez porque tô sendo obrigado".

Mas por quem ele está sendo obrigado a vender por dez se gostaria de vender por doze? A presença de um volume maior de pescado daquela espécie e em condições de qualidade similares em outras bancas faz com que haja uma competição entre os balanceiros e uma queda natural no preço do pescado, todavia a redução do preço só ocorrerá com a aprovação do pescador, proprietário do pescado.

\subsection{2. "Tem preço pra caixa?" - costume e padronização de venda}

O volume mínimo de comércio estabelecido entre os balanceiros é $10 \mathrm{~kg}$. Esta é uma norma do mercado, todavia um outro volume padrão costumeiramente negociado é a "caixa".

Quando um feirante ou qualquer outro comprador questiona o balanceiro se ele "tem preço pra caixa", significa que ele está perguntando se existe disposição do vendedor em oferecer um desconto para compras no volume de $100 \mathrm{~kg}$.

O balanceiro não tem direito a definir o preço de venda do pescado. O desconto não é uma decisão exclusiva do balanceiro, afinal, ele não é proprietário do pescado que comercializa, mas apenas um corretor. A possibilidade de desconto é então discutida com o proprietário do pescado. O balanceiro, em conjunto com o pescador, tem duas opções: reduzir o preço para finalizar seu lote de produto, ou retornar a produção à embarcação ou caminhão, para a venda na madrugada seguinte.
A vantagem aqui é essa. Se der pra eu fazer, faz [...] seria muito cômodo pra mim, eu já teria acabado a nove reais, cê viu quantos já me perguntaram "faz a nove pra caixa?". Mas a figura central é o dono do peixe, o pescador. Se eu seguro o preço, melhora pra ele, melhora pra mim também. A gente é comissionado. Agora realmente quando a feira está acabando e ainda tem muito, das duas uma: ou tu baixa e vende agora ou tu guarda e volta amanhã. Aí é uma questão mais pessoal do pescador. Vai precisar da palavra dele (Balanceiro 1).

\subsubsection{Norma de Crédito e o risco de "Canelada" - norma, risco, confiança e cooperação}

A comercialização na Pedra do mercado do Ver-o-Peso tem uma peculiaridade: a padronização de uma comissão de venda de $6 \%$ ao balanceiro, que representa outra norma de funcionamento deste mercado. Esta comissão tem relação direta com o grau de envolvimento entre o pescador, proprietário da embarcação, muitas vezes tendo financiado seus custos operacionais pelo balanceiro, através da compra de apetrechos de pesca como redes, ou outras necessidades como óleo diesel, rancho ou até mesmo motores, com o compromisso da manutenção do vínculo no momento da comercialização em troca dos riscos financeiros da operação de pesca.

Na verdade, desde quando eu vim pra cá, junto com meu pai, há 20 anos atrás, era cobrado $6 \%[\ldots]$ a gente não empresta dinheiro, não é dessa forma. A gente agencia o barco. Nem juros, a gente não cobra juros. A gente cobra a comissão de venda (Balanceiro 2)

A compra de um motor não é nas mesmas condições. Tem que comprovar renda, cartão de crédito... comércio legal. Se o pescador falhar, não pagar, for embora, me enganar, é meu nome lá (Balanceiro 2).

Por outro lado, a relação entre os balanceiros e feirantes/peixeiros envolve a disponibilização de crédito para que os compradores possam ofertar 
este pescado em outras praças. Nenhum desses créditos é oriundo das instituições financeiras tradicionais, mas viabilizados através do capital de giro dos balanceiros, que assim exercem a função de agentes de fomento e crédito da atividade. Neste momento, o balanceiro exerce a função de fiador das transações, assumindo o risco em caso de inadimplência por parte do comprador e realizando os pagamentos à vista aos pescadores, de acordo com seus acordos de agenciamento das embarcações.

São nestes dois momentos que o balanceiro corre o risco de perder o seu capital: o crédito ao pescador para armar o seu barco em troca do compromisso de fidelidade na venda da produção pesqueira e a venda no "fiado" aos compradores. Estas operações de crédito são operações de risco já que não existem documentos que comprovem sua existência além da palavra.

Leva cinco anos pra tu ter um capital que você pode perder numa manhã (Balanceiro 2).

A gente faz um negócio de risco. Tem gente que me deve 20 mil (reais), nunca me pagou. E são meus amigos até hoje. Não perdi o relacionamento com ele por causa do valor. Ele era pescador mas perdeu tudo (perdeu a rede em uma pescaria). Ele vem aqui mas não tem como me pagar (Balanceiro 2).

E se o comprador não me pagar, eu vou ter que usar dos meus argumentos, eu vou ter que perturbar ele, mas, vamos dizer assim, processar, denunciar, eu não posso protestar em cartório, eu não posso fazer nada (Balanceiro 2).

O fiado é uma relação de confiança entre o balanceiro e os feirantes e demais compradores, estabelecida a partir de uma história de relacionamento entre eles, construída ao longo dos anos, ou indicada por outro balanceiro.

Eu procuro não vender. Dificilmente. Só vendo pra pessoas que conheço há muito tempo (Balanceiro 2).

Ontem tinha um cara que queria comprar 2 toneladas, mas queria dar um cheque ou então depositar na conta. A gente nunca negociou com ele. Assim eu não vendo. Não vendo nem $100 \mathrm{~kg}$ assim, pra quem não conheço, nem 10, na verdade (Balanceiro 3).

O fiado é uma questão de relação entre o balanceiro e o peixeiro. É uma questão de confiança, não existe um papel assinado, não existe um documento assinado, não tem nada. Às vezes o fulano (comprador) já compra fiado com outra pessoa que me indica, e eu passo a vender também pra essa pessoa. E assim vai funcionando esse crédito aqui. Mais na questão da palavra (Balanceiro 3).

Apesar da confiança velada, a "canelada", como assim é chamada por todos, o ato de inadimplência intencional de um dos compradores, é um risco constante. Como mecanismo de defesa do mercado, os balanceiros mantêm diariamente uma conversa informal onde comunicam aos demais sobre "quem está perigoso" (compradores que se encontram em dívida com os mesmos), de tal forma que, se algum outro o vê no mercado, imediatamente comunica ao balanceiro credor sobre a presença do inadimplente no local.

A gente tem uma conversa quase que diária, informal, no fim do dia de venda, principalmente quando tem alguém que tá comprando e não pagando. A gente chama de "canelar". Quando é assim, sai como ratilho de pólvora, todo mundo fala logo: "não vende pra fulano que ele tá perigoso". Mas você decide, mesmo sabendo que deve pra alguém, ele continua vendendo fiado. "Ah, não! Mas pra ele (um determinado balanceiro), ele paga direito" e continua negociando (Balanceiro 1).

\subsection{4. "Como você virou Balanceiro?" - costume}

É costume local a transferência da função de balanceiro entre familiares, tanto pela rentabilidade, apesar das condições de trabalho na madrugada, pelos compromissos herdados, bem como pela experiência adquirida, de forma que 
os costumes se perpetuam e constroem laços cada vez mais fortes.

a família ainda é muito forte nesse meio aqui [...] vai passando de pai pra filho. No meu caso, foi ao contrário. Meus filhos não vieram porque eu não incentivei. Eu não quis que eles viessem..."segue outra profissão, faz o que você gosta". No dia que eu sair daqui, minha dinastia acabou. Mas a maioria aí não, é filho, tem balanceiro que é dono de barco, você sabe disso, o filho dele é advogado, dentista, mas na madrugada, ele é balanceiro. Vamos dizer assim a profissão dele de advogado é na verdade uma renda extra. O ramo da família é o peixe, até quando ele vai ficar nessa relação eu não sei, mas é assim que acontece. Eu sou contador (Balanceiro 1).

A questão de virar balanceiro vem de família pra família. Começou porque meu avô trabalhava na pesca e já tinha um balanceiro que vendia pra ele. Aí meu pai, conforme a gente cresceu, ele tirou esse balanceiro que era o Seu Farias e foi colocando nós. Nós vínhamos pra cá, ficávamos anotando o peso do lado, sabe como é que funciona... aí naturalmente nós fomos assumindo o negócio da família, há mais ou menos 30 anos atrás (Balanceiro 1).

tô com 48 , eu cheguei aqui eu tinha 12 anos, ou seja, minha vida foi aqui (Balanceiro 1).

\subsubsection{Os dias de trabalho - norma}

Até pouco tempo atrás a única exceção ao comércio diário era o segundo domingo do mês de outubro, quando ocorre o Círio de Nazaré, o maior evento religioso do Brasil, concentrando mais de dois milhões de pessoas pelas ruas centrais de Belém. Porém, por conta de orientação jurídica, recentemente nas madrugadas dos domingos também não há mais comércio no local.

Esta é uma nova norma de funcionamento do comércio da Pedra no Ver-o-Peso: a reserva da madrugada do domingo como dia de folga é uma norma coletiva dos balanceiros por orientação de seus advogados sob o risco de ações judiciais por parte de trabalhadores locais que poderiam apresentar queixas trabalhistas indutoras de vínculo empregatício com algum dos balanceiros.

\section{Conclusões e recomendações}

Nesta última seção, são apresentadas conclusões gerais e específicas sobre o funcionamento do comércio atacadista de pescado na Pedra do Ver-o-Peso. Junto às conclusões são apresentadas recomendações destinadas, sobretudo, àqueles que planejam formas de intervenções sobre mercados, sejam eles gestores públicos, pesquisadores ou outros profissionais interessados no assunto.

A constatação é que este mercado possui diversas regras de funcionamento institucionalizadas socialmente ao longo do tempo. Conforme citado por Beckert (2007) e Swedberg (2003), sua organização social, seus costumes, normas, regras e sanções estabelecem uma série de padrões de comportamento que permitem uma expectativa quanto ao comportamento dos demais, em que o desvio de um agente pode representar penalidades no mercado.

A eficiência do processo de comercialização ocorre pela confiança estabelecida entre os agentes, em que pescadores (vendedores) e feirantes (compradores) interagem sob mediação dos balanceiros, enquanto carregadores e viradores aceitam e cumprem suas ordens com precisão. Este contato diário face a face entre balanceiros, seus fornecedores (pescadores) e clientes (feirantes) cria laços de amizade e confiabilidade necessária, capazes de tornarem possíveis as transações, conforme descrito por Sabourin (2011).

Pelo seu papel como figura central do conjunto de operações de embarque e desembarque, os balanceiros podem ser considerados como coordenadores do fluxo logístico do comércio de pescado fresco na Pedra do mercado do Ver-o-Peso.

Outro aspecto relevante é a função-chave dos balanceiros como agentes de fomento e crédito, assumindo os riscos financeiros e a responsabili- 
dade de fazer circular o pescado local no restante da economia. No momento da transação, os pescadores não têm outra garantia de que receberão os pagamentos devidos pelos compradores, uma vez que as transações são geralmente realizadas "no fiado", sendo os balanceiros "validadores" destas transações, pois realizam estes pagamentos aos pescadores no ato da venda.

Os resultados apresentados demonstram como as relações sociais (embeddeness) definem as regras de funcionamento, expostas aqui na forma de falas e comportamentos observados antes, durante e depois das transações comerciais realizadas. A confiança, estabelecida a partir da frequência das transações, é superior ao oportunismo, e as sanções por descumprimento das regras comerciais podem ser tão impactantes socialmente, ao ponto de poderem expulsar definitivamente um agente deste mercado.

Diferente de outros pontos de comercialização aqui, os atravessadores, apesar de seu laço forte com os armadores e pescadores, não detêm o poder de definir preços, uma vez que são meros comissionados e a propriedade do pescado é transferida diretamente do pescador para o comprador, assumindo o atravessador o papel de coordenador do processo de distribuição de pescado e dos riscos dessa operação, sendo remunerado por tal serviço em $6 \%$ do valor de venda.

A intervenção pública destinada a reduzir o número de atravessadores com os Terminais Pesqueiros Públicos (TPPs) não foi acompanhada de uma análise sociológica dos impactos destas intervenções sobre aqueles que direta ou indiretamente estão envolvidos com a atividade. A estimativa destes impactos é de difícil previsão, uma vez que os agentes de mercado buscam alternativas diversas daquelas imaginadas pelos analistas.

Com esse trabalho, espera-se contribuir para a formação de novos modelos de análises de cadeia produtivas do agronegócio e da agricultura familiar baseados nos pressupostos da Sociologia Econômica, em especial aqueles diretamente envolvidos com comunidades pesqueiras e aquícolas. Espera-se também que este trabalho permita um olhar diferenciado ao Poder Público, a partir de uma perspectiva baseada nas motivações individuais e coletivas, nas relações estabelecidas entre os agentes e na construção social dos mercados, contextos que extrapolam o pressuposto econômico da oferta e demanda, em que a palavra-chave é a imersão social (social embeddedness).

\section{Referências}

AUGUSTO, C. A. et al. Pesquisa Qualitativa: rigor metodológico no tratamento da teoria dos custos de transação em artigos apresentados nos congressos da Sober (2007-2011). RESR, Piracicaba-SP, v. 51, n. 4, p. 745-764, out./dez. 2013.

BALLOU, R. H. Gerenciamento da Cadeia de Suprimentos: logística empresarial. 5. ed. São Paulo: Bookman, 2006.

BARTHEM, R. O desembarque na região de Belém e a pesca na foz amazônica. In: BECKERT, J. The social order of markets. MPIFG Working Paper 07/12, 2007.

BRASIL. Ministério da Pesca e Aquicultura. Boletim Estatísticoda Pescae Aqüicultura. Brasília, 2010. Disponível em: <http://www.mpa.gov.br/index.php/topicos/300boletim-estatistico-da-pesca-e-aquicultura-2010>.

CAPELLESSO. A. J. e CAZELLA, A. A. Os Sistemas de Financiamento na Pesca Artesanal: um estudo de caso no Litoral Centro-Sul Catarinense. RESR, Piracicaba-SP, v. 51, n. 2, p. 275-294, abr.jun. 2013.

CARVALHO NETO, R. A. Modelo de análise de redes sociais aplicado à cadeia logística do agronegócio de base econômica familiar. Dissertação de mestrado, Universidade Católica de Brasília, Brasília, 2009.

FLIGSTEIN, N. Marketis as politics: political-cultural approach to market institutions. American Sociological Review, v. 61, 1996. p. 656-673.

GRANOVETTER, M. Economic Action and Social Structure: The Problem of Embeddedness. The American Journal of Sociology, v. 91, n. 3, nov. 1985, p. 481-510.

LEITÃO, W. M. e CORRÊA, M. C. S. Pescadores, balanceiros, vendedores de café: trabalhadores da Pedra do Ver-o-Peso. In: LEITÃO, W. M. (Org.). Ver-oPeso: estudos antropológicos no Mercado de Belém. Belém: NAEA, 2010. p. 103-131.

McMILLAN, J. A reinvenção do bazar: uma história dos mercados. Tradução: Sérgio Goes de Paula. Rio de Janeiro, Jorge Zahar Ed. 2004.

MÖLLERING, G. Marketing constitution analysis: a new framework applied to Solar Power Technology Markets. MPIfG Working Paper 09/07. 2009. 
NOVAES, A. G. Logística e gerenciamento da cadeia de distribuição. Estratégia, Operação e Avaliação. Rio de Janeiro: Elsevier, 2007.

POLANYI, K. A grande transformação: as origens da nossa época. Tradução: Fanny Wrobel. 2 $2^{\underline{a}}$ ed. Rio de janeiro: Editora Elsevier, 2012

PUTNAM, R. Making democracy work. New Jersey: rinceton University Press, 1993.

RUFFINO, M. L. O setor pesqueiro na Amazônia: situação atual e tendências. Coleção Estudos Estratégicos. ProVárzea - Projeto Manejo dos Recursos Naturais da Várzea, Brasília: Instituto Brasileiro do Meio Ambiente e dos Recursos Naturais Renováveis - IBAMA, MMA 2007.

SABOURIN, R. Manejo dos recursos comuns e reciprocidade: os aportes de Elinor Ostrom ao debate. Sustentabilidade em Debate, v. 1, n. 2, p. 141158, 2010.

Sociedade e organizações camponesas. Uma leitura através da reciprocidade. Porto Alegre: UFRGS, 2011.

STEINER, P. A. Sociologia econômica. São Paulo: Atlas, 2006.

SWEDBERG, R. Principles of Economic Sociology. Princeton University Press, 2003.

TELLES, R. e STREHLAU, V. I. Canais de Marketing $\mathcal{E}$ Distribuição Conceitos, Estratégias, Gestão, Modelos de Decisão. São Paulo: Saraiva, 2006.

VIANA, L. F. C. O savoir-faire das cafeterias na extração de cafés especiais: rotinas e processo de valoração. Dissertação de Mestrado. Faculdade de Agronomia e Medicina Veterinária, Universidade de Brasília, Brasília, 2014, 124 p. 